\title{
A Google Earth-based database management for schistosomiasis control in Zanzibar
}

\author{
Ming-Zhen He, ${ }^{1,2}$ Wei Li, ${ }^{1,3}$ Saleh Juma, ${ }^{4}$ Fatma Kabole, ${ }^{4}$ Da-Cheng Xu, ${ }^{5}$ Xin-Yao Wang, ${ }^{1,3}$ \\ Jian He, ${ }^{1,3}$ Tao Jiang, ${ }^{6}$ Robert Bergquist, ${ }^{7}$ Kun Yang ${ }^{1,3}$ \\ ${ }^{1}$ Jiangsu Institute of Parasitic Diseases, Key Laboratory of National Health Commission on Parasitic \\ Disease Control and Prevention-Jiangsu Provincial Key Laboratory on Parasite and Vector Control \\ Technology, Wuxi, Jiangsu, China; ${ }^{2}$ Center for Disease Control and Prevention of Changzhou City, \\ Changzhou, Jiangsu, China; ${ }^{3}$ College of Medicine, Jiangnan University, Wuxi, Jiangsu, China; ${ }^{4}$ Ministry of \\ Health of Zanzibar, Zanzibar, United Republic of Tanzania; ${ }^{5}$ Center for Disease Control and Prevention of \\ Jintan District, Changzhou, Jiangsu, China; ${ }^{6}$ Center for Disease Control and Prevention of Danyang City, \\ Zhenjiang, Jiangsu, China; ${ }^{7}$ Ingerod, Brastad, Sweden
}

\begin{abstract}
Schistosomiasis remains a serious health problem in Africa. Although a strong, coordinated agenda for research on this disease has been in place for the last 50 years in Zanzibar, data storage, retrieval of survey data and management remain problem areas. We investigated the use of Google Earth (GE) in conjunction with
\end{abstract}

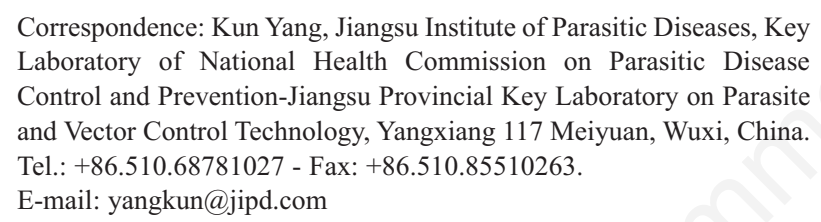

Key words: Google Earth; GPS; Schistosomiasis; Snail; Database; Data management; Zanzibar.

Contributions: KY designed the study; MZH, WL, SJ, FK, DCX, XYW, $\mathrm{JH}$ and JRD collected, analyzed and interpreted data; MZH and KY drafted the article; RB revised the manuscript. All authors reviewed and revised the first and final drafts of this manuscript.

Conflict of interest: the authors declare no potential conflict of interest.

Funding: this work was funded by the Ministry of Commerce of the People's Republic of China (No. 2015400302209101); this project was supported by applied research project control of schistosomiasis, parasitic disease and endemic diseases of Jiangsu Province (No. X201807), and project of invigorating health care through science, technology and education.

Received for publication: 19 September 2018.

Revision received: 8 December 2018.

Accepted for publication: 13 December 2018.

(C) Copyright M-Z. He et al., 2019

Licensee PAGEPress, Italy

Geospatial Health 2019; 14:740

doi:10.4081/gh.2019.740

This article is distributed under the terms of the Creative Commons Attribution Noncommercial License (CC BY-NC 4.0) which permits any noncommercial use, distribution, and reproduction in any medium, provided the original author(s) and source are credited. a hand-held, global positioning system as a pilot project for managing schistosomiasis control. In this way, risk areas can be surveyed and followed up by visualizing both the distribution of human infections and that of the intermediate snail host together with environmental information. A platform with three spatial databases was created: i) distribution of infected humans; ii) distribution of the intermediate snail host in ponds (infected and not infected specimens); iii) distribution of the intermediate snail host in streams (infected and non-infected specimens). The GE spatial database increased the efficiency of follow-up case treatment as well as snail control and contributed also to the discovery of previously unknown areas in need of snail control. We conclude that this platform is advantageous not only by being useful for management and visualization of spatial data, but also because it is easy to operate and available free of charge.

\section{Introduction}

Schistosomiasis, one of the poverty-related, neglected tropical diseases (NTDs), is caused by trematode parasites of the genus Schistosoma, which reside in the abdominal capillaries of the infected human definitive host. Different kinds of snails play the role of intermediate host depending on the species of the parasite. So far, many areas in sub-Saharan Africa still have a high schistosomiasis prevalence with many people presenting with high intensities of disease due to constant reinfection (Olsen et al., 2015). The World Health Organization (WHO) estimates that more than $90 \%$ of all humans requiring treatment for this disease currently live in Africa (WHO, 2018). In Zanzibar (including the islands of Unguja and Pemba), urogenital schistosomiasis is still a considerable public health problem with high prevalence (Knopp et al., 2013; Pennance et al., 2016). Schistosomiasis on these islands is urogenital which is caused by Schistosoma haematobium relying on the intermediate host snail Bulinus globosus (Allan et al., 2013).

In 2012, WHO set the goal to interrupt transmission of schistosomiasis in selected countries of the African region by 2025 (WHO, 2013). Much work and research have been carried out to reach this goal in Zanzibar. Prevention and control on the island of Pemba was once the focus of strong control efforts (Savioli et al., 1989; Savioli and Mott, 1989; Lwambo et al., 1997; Guidi et 
al., 2010); however, although disease burdens have been alleviated through preventative chemotherapy together with additional control interventions, transmission has not been interrupted on a large scale (Knopp et al., 2012; 2013; 2016). Regrettably, collected data are dispersed and scattered and cannot be effectively utilized since the local schistosomiasis control institution, the NTD office, has neither access to easily available information about the distribution of B. globosus nor to environmental data associated with this infection. At the World Health Assembly on May 21st 2014, the Government of Zanzibar, WHO and China jointly signed a memorandum of understanding to cooperate in the control of schistosomiasis in Zanzibar. This multilateral cooperation resulted in the decision to conduct a pilot project with the aim of eliminating schistosomiasis in this part of Tanzania. In August 2016, Jiangsu Institute of Parasitic Disease in Wuxi, China officially took on this China-aid project for schistosomiasis elimination in Zanzibar. The project was stationed on Pemba Island and a systematic disease investigation and snail survey was initiated together with the local NTD office. It was felt that the work should focus on the spatial component to establish effective data collection and management for schistosomiasis control using geographical information systems (GIS) based on the Google Earth (GE) platform (Google Inc., Mountain View, CA, USA), which is a free software displaying geographic data.

Elliott and Wartenberg (2004) pointed out the importance of spatial epidemiology and a review by Bergquist and Rinaldi (2010) noted the usefulness of remote sensing (RS) for healthrelated research on endemic diseases. GE integrates the functions of RS, GIS and global positioning (GPS) technologies to present users with satellite-generated aerial imagery that varies from the global scale to the local (Lisle, 2006). Combined with GIS software, e.g., ArcGIS (ESRI, Redlands, CA, USA), and network technology, GE is an excellent approach to spatial epidemiology as various files used for the collection of data, e.g., Excel and shapefiles. Such files can easily be reformatted and incorporated as keyhole markup language (KML) files, a commonly used format pioneered by Keyhole Inc., which was acquired by Google in 2004. The shapefile is a popular geospatial vector data format developed by ESRI for interoperability between various software products. Human residences as well as streams and ponds are spatially represented as points, lines and polygons, respectively. A large number of different annotations describing these vectors, such as name, environmental variables, infection status, etc., can be added as annotations.

The GE virtual globe approach incorporates aerial images, digital terrain and a large amount of basic geographic information, the utilization of which is simple and convenient. Collected data can be accurately recorded and zooming makes it possible to present geographically limited areas as flat maps where the landscape scenes can be intuitively understood with distances and areas derived in a straightforward way. The spatial data management methods applicable to basic schistosomiasis control work on Pemba were explored by adopting the GE platform to establish a spatial database for the demonstration of the distribution of human schistosomiasis infections and the presence of the intermediate snail host in the various water bodies available on the island. The specific aim of this work was to improve management of schistosomiasis control in Zanzibar by investigating the spatial relation between infected humans and B. globosus habitats.

\section{Materials and Methods}

\section{Time and area under study}

S. haematobium prevalence and snail status on Pemba Island was surveyed from February 2017 to May 2018. The island is divided into four districts that are further divided into about 120 smaller administrative areas, referred to as shehias, which can contain several villages varying in population size and household number. The total area of Pemba Island is $984 \mathrm{~km}^{2}$, and the average area of a shehia is $8.2 \mathrm{~km}^{2}$.

\section{Data records and generation of spatial coordinates}

The data consisted of geographic information, such as the whereabouts of human residences, ponds and streams. All findings regarding these entities, such as diagnostic results and snail data, etc., were named attribute data and given unique identification numbers (ID), for example for the human cases the record included name, house location, laboratory test results and treatment (Shehia no./Village no./Household no./Person no.).

\section{Human data}

Schistosomiasis-related data included the infection rate for each shehia and individual case investigation of positive cases. There are around 3,000 people in each shehia on Pemba Island. The whole population were surveyed in four pilot shehias, i.e. Mtangani, Kiyuyu, Wingwi and Uwandani. In other shehias, about 200 residents (including at least 30 children aged 9-12 years) from 50 households were randomly selected and surveyed. Urine samples were collected and $10 \mathrm{ml}$ of each sample was filtered and subjected to microscopy by experienced laboratory technicians who recorded all $S$. haematobium eggs present for each individual. All this information was recorded in an Excel database.

\section{Snail data}

Snail survey was conducted after the rainy season. All water bodies in the project area were investigated. The snail data included the distribution of B. globosus in the environment inhabited by humans and included the number of surveyed sites (ponds and streams), the total number of snails and the number of infected ones. The ponds were encoded as Shehia no./Village no./Serial no./Pond type, while the streams were only labelled with its serial no. according to order of investigation. The sites were surveyed for snails at distance gaps of 30 and $100 \mathrm{~m}$, respectively. At each identified site, presence of $B$. globosus was searched for 15 min over a maximum $15 \mathrm{~m}^{2}$ area. The borders of the water bodies and their vegetation, where snails are most likely to be found, were more intensively searched than other areas. B. globosus was preliminary identified upon shell morphology, placed in screw top plastic containers with freshwater, and taken to the laboratory for microscopic examination of cercariae after crushing. A handheld Garmin etrex 30x device (Kansas City, KS, USA) was used to specify the coordinates of all findings. All data were saved as KML files through BaseCamp software, version 4.5.2 (Garmin).

\section{Annotating attribute data}

Positive human cases were recorded as a point on the map and the total number counted, while the length of the streams, given as lines, and the surface area of the ponds, given as polygons, were 
measured using the GE properties window and recorded in the Excel database. Water bodies without snails were given blue colour, those with presence of non-infected snails yellow and those with presence of infected snails red. These spatial, qualitative pieces of information, each identified by its ID, were saved as shapefiles, reformatted as KML files and subsequently imported into GE Pro, version 7.1.8.3036 (Google).

\section{The spatial database}

The spatial, qualitative pieces of information, each identified by its ID, were collected in a GIS database, reformatted by ArcGIS, version 10.2.2 (ESRI) as KML files and subsequently imported into GE Pro, version 7.1.8.3036 (Google) to display the distribution of positive human cases in their environment and the snails (infected and uninfected) in theirs (ponds and streams). In this way, a GIS database containing the coordinates of all human positive cases found, including the status of the surrounding ponds and streams was established. Digital maps and shapefiles of Pemba Island were obtained from the NTD office and associated with the collected schistosomiasis data with reference to the shehias so that the GIS database could tell the schistosomiasis infection rate in all the different shehias on the island. Managed this way, all geographic and attribute data would be available and possible to visualize by using the software and clicking on the object in question.

\section{Training}

The Chinese team trained the local NTD staff on the operation of GE and how to use a handheld GPS device to specify the coordinates of all findings, save tracks and mark points, lines and polygons, how to import GPS data into GE as well as how to measure distances and how to calculate areas. The staff was also trained to use ArcGIS software manipulating ArcGIS shapefile vector features of interest such as points, lines and polygons, here representing human infections, streams and ponds, respectively, and converting this format into KML files to be fed into the GE software. They were also trained in associating attribute data related to the spatial data collected so as to create spatial databases.

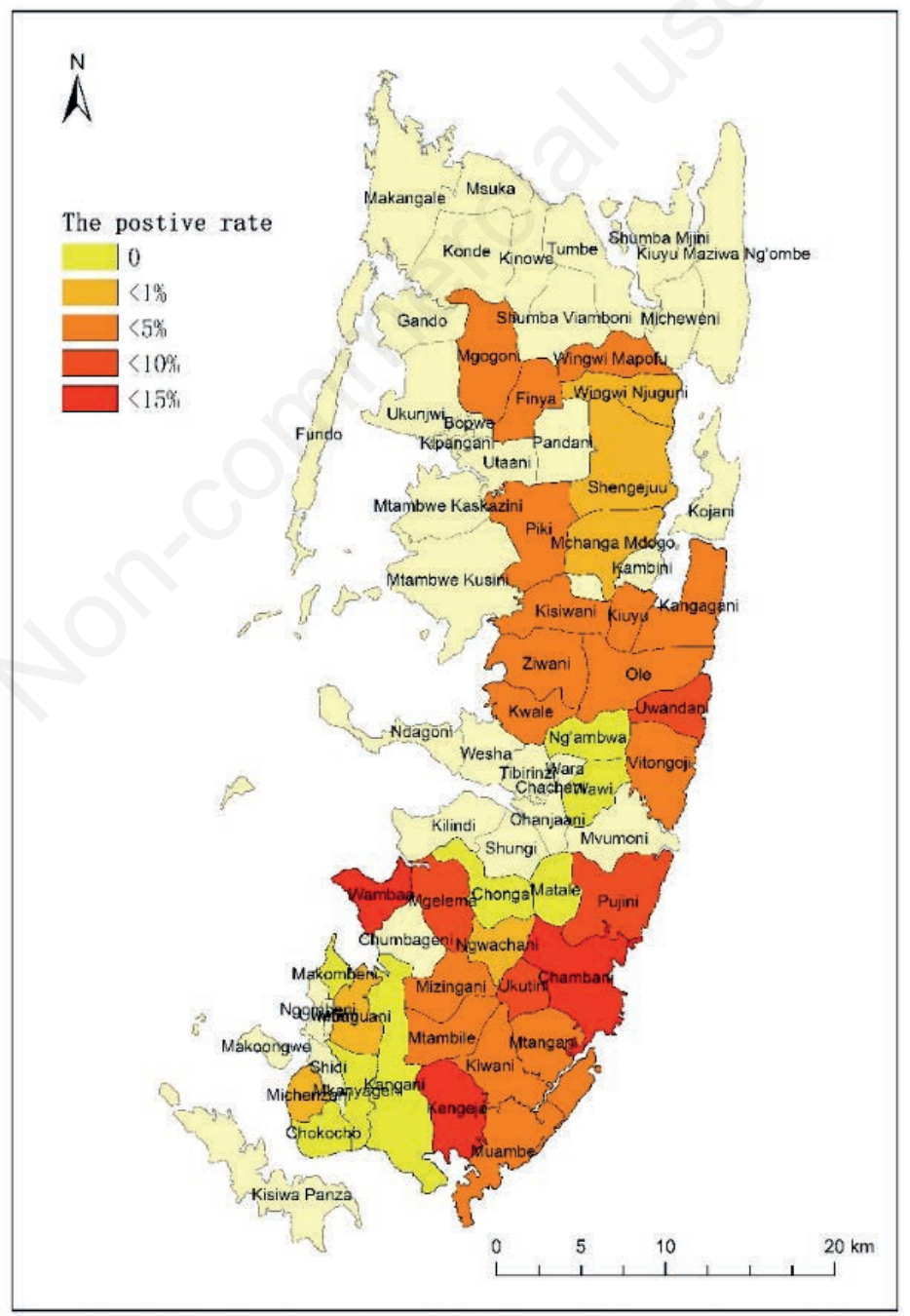

Figure 1. Prevalence of $S$. haematobium in 38 surveyed shehias on Pemba Island. 


\section{Results}

\section{Surveys}

From Feb 2017 to May 2018, a total of 38 shehias were investigated for $S$. haematobium infection. A total of 17,674 urine samples were collected and 546 were found to be positive corresponding to an average positive rate of $3.1 \%$. Figure 1 shows the prevalence rates in the surveyed 38 shehias on Pemba Island.

\section{Spatial databases}

Three spatial databases were created by means of GE and they included distribution of infected humans (191 persons in 8 shehias); distribution of the intermediate snail host in ponds (all the ponds surveyed in 20 shehias); and distribution of the intermediate snail host in streams (all the streams surveyed in 38 shehias) (Figure 2).

\section{Infected humans}

The diagnostic examination showed that 191 persons in the 8 shehias were infected. The coordinates of these residences were available in the database that had been established and the ID and name, householder name, egg counts and treatment were recorded in the attribute data for each positive case. They could then be visualized and marked on GE as shown in Figure 3. The attribute information of each case could be displayed by clicking on the point in question.

\section{Snail distribution}

A total of 117 ponds in the 20 shehias were surveyed for B. globosus (Figure 4). The total area of the ponds surveyed was $2,052,965 \mathrm{~m}^{2}$. Although we found 36 ponds with $B$. globosus covering an area of $1,133,724 \mathrm{~m}^{2}$ only $14\left(808,194 \mathrm{~m}^{2}\right)$ were harboured infected B. globosus. Figure 5 shows ponds without snails, ponds with non-infected snails and ponds with infected snails. The basic information and snail information for each pond could be displayed by clicking on that pond shown in GE.

In the shehia of Uwandani, four infected ponds were found in August 2017, and nearly 200 positive cases were found in the whole population survey. The location of human cases and infected waterbodies were displayed on GE, and we found there were no infected ponds nearby some human cases. Then the waterbodies and snail situation were investigated again, and another two infected ponds surrounding the human cases were found (Figure 6).

A total of 72 streams in the 38 shehias were surveyed as shown in Figure 4. The total length of the streams surveyed was $183 \mathrm{~km}$. We found 44 streams with $B$. globosus, out of which 6 harboured infected snails. Figure 7 shows streams without snails, streams with snails and streams with infected snails. The basic information and snail information for each stream could be displayed by clicking on that stream in the software.

\section{Training}

After training and work practice, all NTD staff easily grasped the use of GPS and GE. They could utilize GPS devices to specify coordinates and save tracks and use GE to import GPS data. They

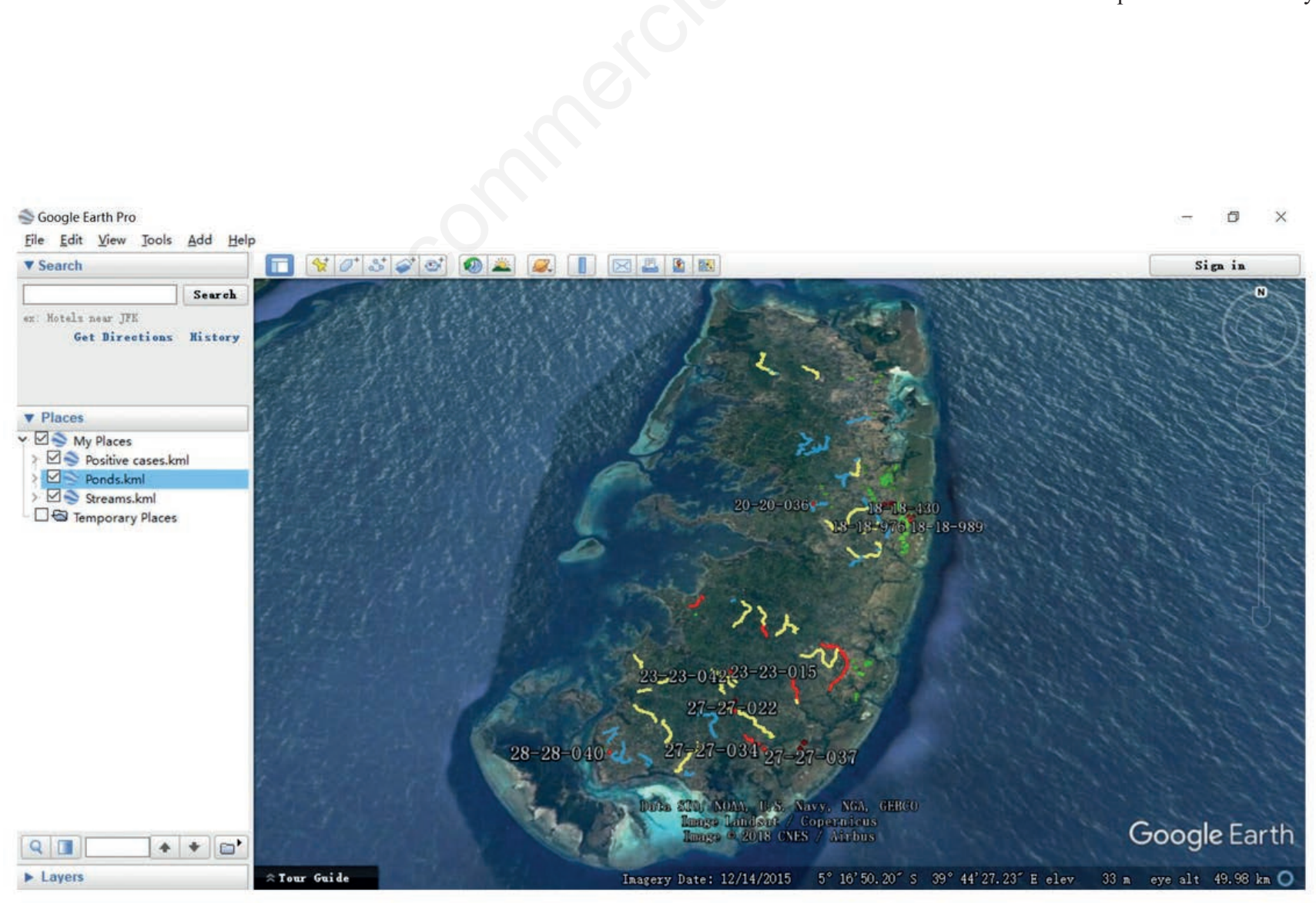

Figure 2. Display of how three different spatial databases can be simultaneously visualized via Google Earth. 


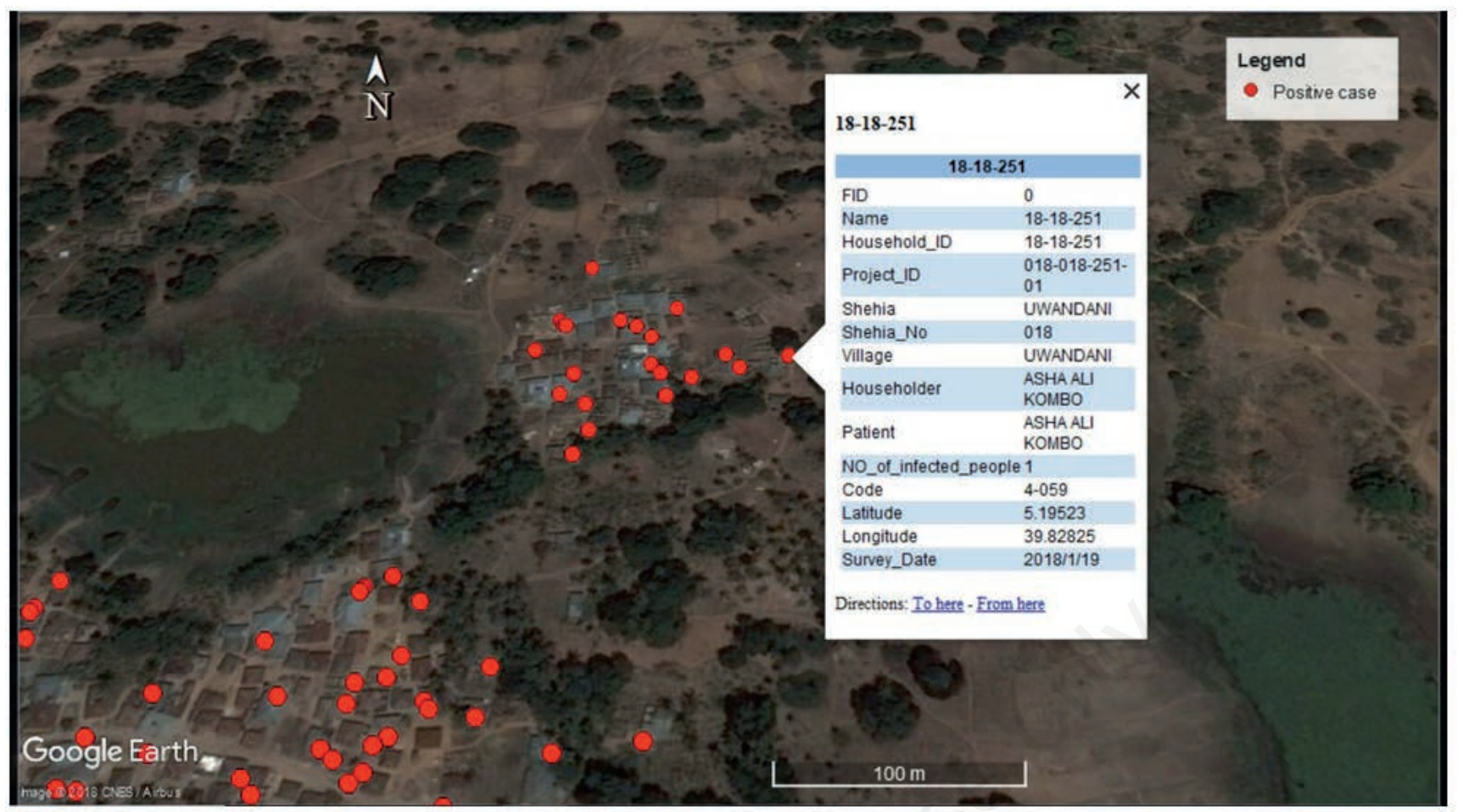

Figure 3. Distribution of positive human cases and display of annotated information of cases.

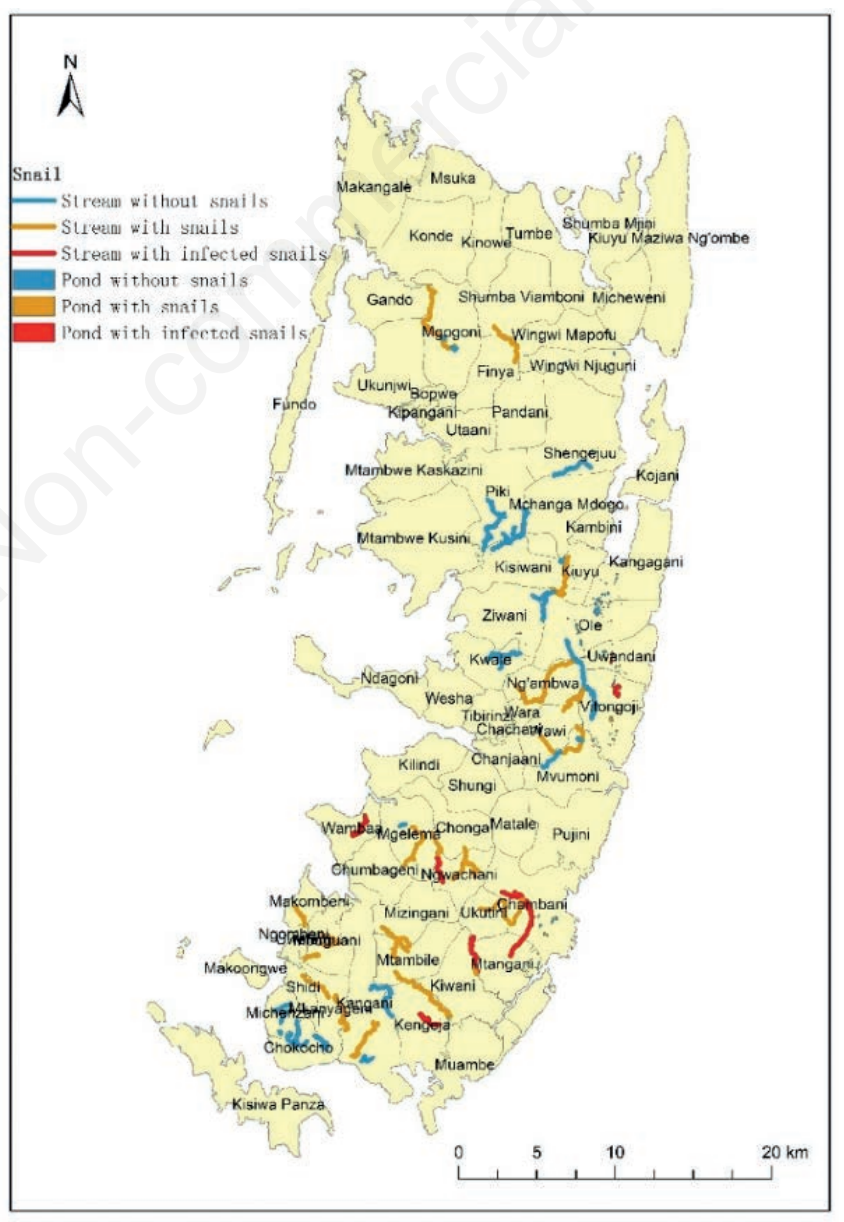

Figure 4. Distribution of B. globosus in ponds and streams surveyed in 38 shehias on Pemba Island. 
could also measure distances and areas and use ArcGIS to convert shapefile vector files to KML files, create spatial databases and make maps.

\section{Discussion}

Many diseases show spatial clustering (Elliott and Wartenberg, 2004; Kirby et al., 2017), including parasitic diseases (Barbosa et al., 2014; Hundessa et al., 2016), other infectious diseases (Smith et al., 2015; Lai et al., 2018) and also non-communicable diseases like cancer (Goodman et al., 2014; Sun et al., 2015). Schistosomiasis transmission is focal in nature (Manyangadze et al., 2016) and schistosomiasis cases are consequently also spatially clustered as shown in many studies (Brooker et al., 2006; Clements et al., 2006; Simoonga et al., 2008). Also, the intermediate snail host has the tendency to appear in cluster (Cheng et al., 2016; Gao et al., 2014). It follows that spatial data collection are important for schistosomiasis control. Indeed, this helped us to identify four infected ponds in Uwandani that had not been found until we located the human cases near these ponds.

On Pemba, B. globosus is the only intermediate host of $S$. haematobium, so the geographical distribution of this snail species determines the spatial distribution of schistosomiasis on the island. Clennon et al. (2004) has already shown that households with high infection intensities of $S$. haematobium were significantly clustered around a water body with infected snails near the southern coast of Kenya. Following this lead, we established a spatial database of distribution of positive cases, together with the distribution of B. globosus in ponds and streams based on GPS and GE, which helped following up cases as well as guide us to other key areas in need of snail control as mentioned above.

GE is increasingly applied to the study of infectious diseases (Escamilla et al., 2014; Simonsen et al., 2016). For example, it was used to map HCV infections by home, social, and sexual neighbourhoods among community-recruited men who have sex with men in New York City (Tieu et al., 2018). In another study, Google Earth imagery and geographical analysis software was used to develop a sampling frame by digitizing and assigning coordinates for each household within the catchment area (Escamilla et al., 2014). The GE platform is particularly useful for research on schistosomiasis (Clennon et al., 2004; Clements et al., 2006; Simoonga et al., 2008, 2009; Yang et al., 2012; Sun et al. 2014; Gao et al., 2014; Wang et al., 2014; Manyangadze et al., 2015; Xiao et al., 2016a, 2016b). A great advantage is that GE users need not be computer specialists since its operation is straightforward and the software easy to apply, e.g., for map creation (Lefer et al., 2008) which is the first step. As long as the computer is connected to Internet, any map can be rapidly displayed. The application of GE in grass-root schistosomiasis control institutions is therefore a useful platform for the storage and display of spatial data (Wang et al., 2014; Xiao et al., 2016a). Combined with GIS software, such as ArcGIS, GE is also reliable for surveillance and forecasts (Xiao et al., 2016b) and can be implemented for epidemiological monitoring and the development of early warning systems (EWS) (Simonsen et al., 2016).

An on-site trial with GE as the operative platform achieved good results. Indeed, already after a few weeks of simple training and some practice, the NTD staff mastered all the different steps from recording results to displaying them. The spatial data were

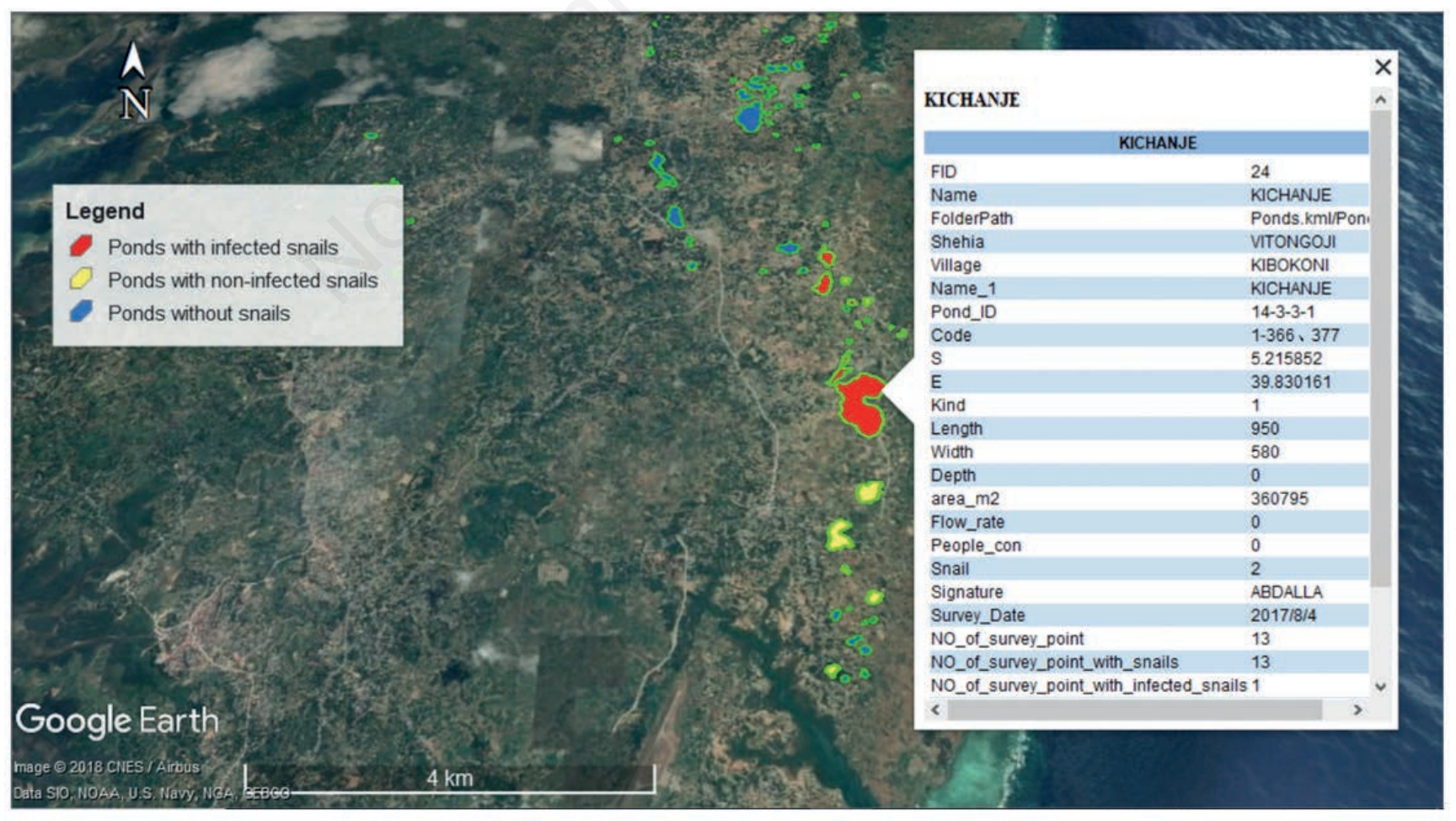

Figure 5. Distribution of B. globosus in ponds and display of annotated information of ponds. 
first generated using the coordinates taken from the GPS device adding attribute information for human cases and snails previously recorded in Excel. Secondly, both spatial and attribute data were organically integrated via ArcGIS establishing the GIS database, which made it possible to effectively manage and utilize the large number of epidemiological data collected. ArcGIS permits the provision of various thematic maps of the distribution of both human cases and positive snails. This database can also be used for infor-
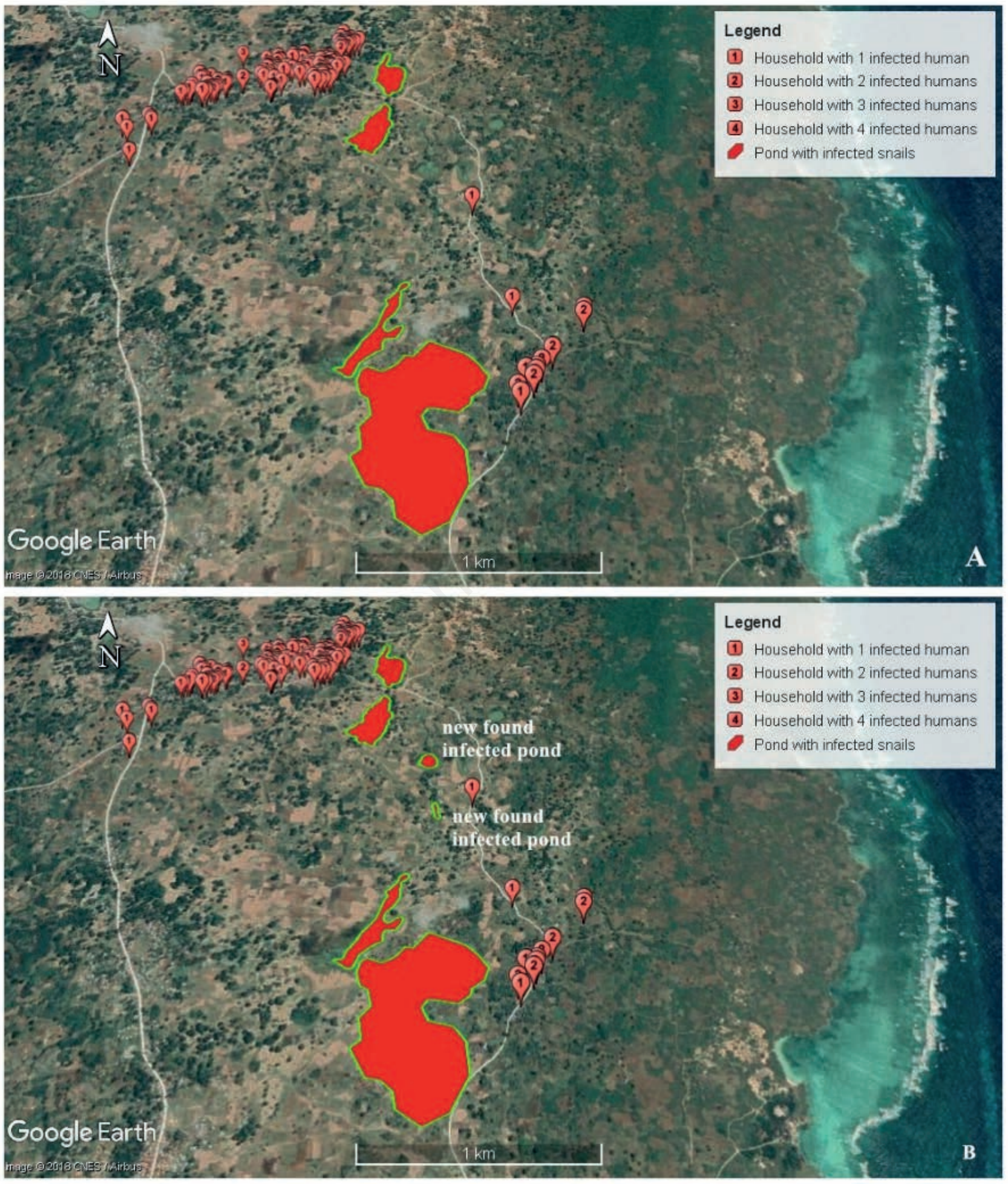

Figure 6. Two new infected ponds found in Uwandani by analysing the location of human cases and infectious ponds. 


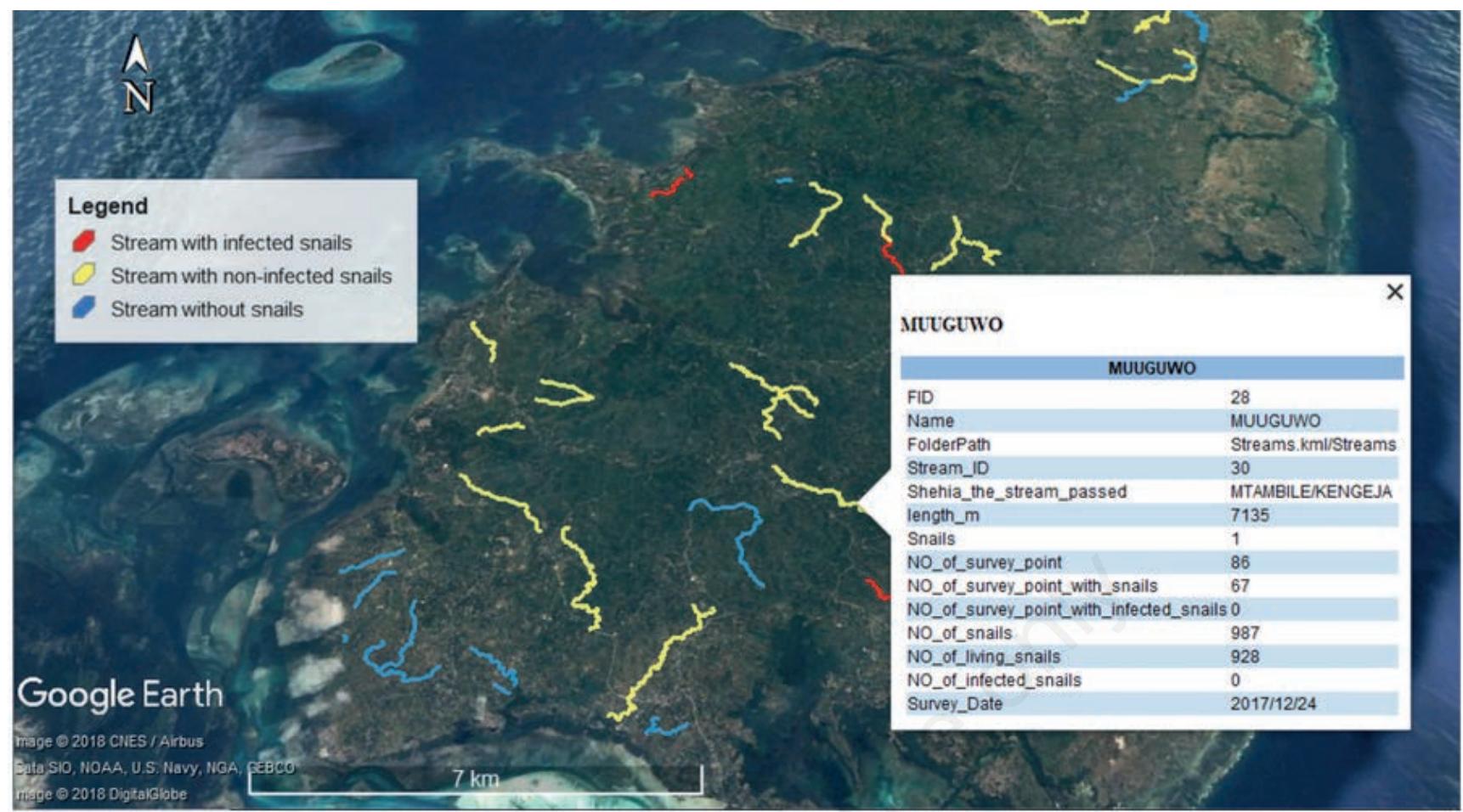

Figure 7. Distribution of B. globosus in streams and display of annotated information of streams.

mation query and statistical analysis. After the establishment of the GIS database, ArcGIS provided the link to GE through the conversion of shapefiles to KML files and thus clearly visualize the geographic position of positive cases as well as ponds and streams with infected snails, while attribute data, such as case information or snail distribution information, were only a click away. According to the needs, a certain type of data can be selected for display on the map, or multiple different types of data can be displayed at the same time, easily visualizing the degree of severity of the endemic situation. We could also explore the spatial relation between infected human cases and B. globosus habitats by analysing the location of human cases and water bodies.

There are some limits in this study. For snail classification, we just conducted preliminary identification using shell morphology, while it is advisable to apply molecular diagnosis based on DNA detection for further identification. Secondly, the location of households with infected cases is not a proxy of where transmission takes place. In the next step, the proximity of a household to the nearest water body could be used to identify clusters of infected cases which might point towards a transmission source.

It should be borne in mind that, in contrast to complete eradication of a disease, elimination means controlling it so well that it no longer is of public health importance. However, it should also be remembered that keeping a disease eliminated in the face of ongoing transmission can be a tall order in the absence of strong economic development. A surveillance tool like GE that can connect all information needed and also play the role of EWS would be most useful for the rapid deployment of an effective response. As such, GE would not only be useful on Pemba but also in other countries on the African continent and elsewhere.

\section{Conclusions}

It might seem possible to also eradicate schistosomiasis on an island like Pemba as the authorities there should be able to introduce visitor controls isolating it from influx of the infection from surrounding endemic areas. As a free software, the technique of GE proved applicable and useful for spatial data management for schistosomiasis control. Based on this platform, the severity of schistosomiasis distribution and snail situation can be judged intuitively and timely, supporting the identification and location of transmission sites as well as communities at high risk. Therefore, it can support planning and contribute to timely application of control measures by the health services. Our experience with training of staff without previous knowledge of advanced use of computers and GPS instruments for the collection and display of epidemiological data was very positive. All NTD staff easily grasped the use of GPS and GE and quickly applied this new knowledge for the collection of data, adding coordinates and saving tracks. They could also quickly learn how to measure distances and areas and use ArcGIS to convert shapefile vector files to KML files, thereby creating spatial databases and produce the maps needed.

\section{References}

Allan F, Dunn AM, Emery AM, Stothard JR, Johnston DA, Kane RA, Khamis AN, Mohammed KA, Rollinson D, 2013. Use of sentinel snails for the detection of Schistosoma haematobium transmission on Zanzibar and observations on transmission 
patterns. Acta Trop 128:234-40.

Barbosa DS, Belo V, Rangel ME, Werneck GL, 2014. Spatial analysis for identification of priority areas for surveillance and control in a visceral leishmaniasis endemic area in Brazil. Acta Trop 131:56-62.

Bergquist R, Rinaldi L, 2010. Health research based on geospatial tools: a timely approach in a changing environment. J Helminthol 84:1-11.

Brooker S, Alexander N, Geiger S, Moyeed RA, Stander J, Fleming F, Hotez PJ, Correa-Oliveira R, Bethony J, 2006. Contrasting patterns in the small-scale heterogeneity of human helminth infections in urban and rural environments in Brazil. Int J Parasitol 36:1143-51.

Cheng G, Li D, Zhuang D, Wang Y, 2016. The influence of natural factors on the spatio-temporal distribution of Oncomelania hupensis. Acta Trop 164:194-207.

Clements AC, Lwambo NJ, Blair L, Nyandindi U, Kaatano G, Kinung'hi S, Webster JP, Fenwick A, Brooker S, 2006. Bayesian spatial analysis and disease mapping: tools to enhance planning and implementation of a schistosomiasis control programme in Tanzania.Trop Med Int Health 11:490503.

Clennon JA, King CH, Muchiri EM, Kariuki HC, Ouma JH, Mungai P, Kitron U, 2004. Spatial patterns of urinary schistosomiasis infection in a highly endemic area of coastal Kenya. Am J Trop Med Hyg 70:443-8.

Elliott P, Wartenberg D, 2004. Spatial epidemiology: current approaches and future challenges. Environ Health Perspect 112:998-1006.

Escamilla V, Emch M, Dandalo L, Miller WC, Martinson F, Hoffman I, 2014. Sampling at community level by using satellite imagery and geographical analysis. Bull World Health Organ 92:690-4.

Gao FH, Abe EM, Li SZ, Zhang LJ, He JC, Zhang SQ, Wang TP, Zhou XN, Gao J, 2014. Fine scale Spatial-temporal cluster analysis for the infection risk of Schistosomiasis japonica using space-time scan statistics. Parasit Vectors 7:578.

Goodman M, LaKind JS, Fagliano JA, Lash TL, Wiemels JL, Winn DM, Patel C, Van Eenwyk J, Kohler BA, Schisterman EF, Albert P, Mattison DR, 2014. Cancer cluster investigations: review of the past and proposals for the future. Int J Environ Res Public Health 11:1479-99.

Guidi A, Andolina C, Makame Ame S, Albonico M, Cioli D, Juma Haji H, 2010. Praziquantel efficacy and long-term appraisal of schistosomiasis control in Pemba Island. Trop Med Int Health 15:614-8.

Hundessa SH, Williams G, Li S, Guo J, Chen L, Zhang W, Guo Y, 2016. Spatial and space-time distribution of Plasmodium vivax and Plasmodium falciparum malaria in China, 2005-2014. Malar J 15:595.

Kirby RS, Delmelle E, Eberth JM, 2017. Advances in spatial epidemiology and geographic information systems. Ann Epidemiol 27:1-9.

Knopp S, Mohammed KA, Ali SM, Khamis IS, Ame SM, Albonico M, Gouvras A, Fenwick A, Savioli L, Colley DG, Utzinger J, Person B, Rollinson D, 2012. Study and implementation of urogenital schistosomiasis elimination in Zanzibar (Unguja and Pemba islands) using an integrated multidisciplinary approach. BMC Public Health 12:930.

Knopp S, Person B, Ame SM, Mohammed KA, Ali SM, Khamis IS, Rabone M, Allan F, Gouvras A, Blair L, Fenwick A,
Utzinger J, Rollinson D, 2013. Elimination of schistosomiasis transmission in Zanzibar: baseline findings before the onset of a randomized intervention trial. PLoS Negl Trop Dis 7:e2474.

Knopp S, Person B, Ame SM, Ali SM, Muhsin J, Juma S, Khamis IS, Rabone M, Blair L, Fenwick A, Mohammed KA, Rollinson D, 2016. Praziquantel coverage in schools and communities targeted for the elimination of urogenital schistosomiasis in Zanzibar: a cross-sectional survey. Parasit Vectors 9:5.

Lai WT, Chen CH, Hung H, Chen RB, Shete S, Wu CC, 2018. Recognizing spatial and temporal clustering patterns of dengue outbreaks in Taiwan. BMC Infect Dis 18:256.

Lefer TB, Anderson MR, Fornari A, Lambert A, Fletcher J, Baquero M, 2008. Using Google Earth as an innovative tool for community mapping. Public Health Rep 123:474-80.

Lisle RJ, 2006. Google Earth:a new geological resource. Geol Today 22:29-32.

Lwambo NJ, Savioli L, Kisumku UM, Alawi KS, Bundy DA, 1997. The relationship between prevalence of Schistosoma haematobium infection and different morbidity indicators during the course of a control programme on Pemba Island. Trans R Soc Trop Med Hyg 91:643-6.

Manyangadze T, Chimbari MJ, Gebreslasie M, Mukaratirwa S, 2015. Application of geo-spatial technology in schistosomiasis modelling in Africa: a review. Geospat Health 10:99-110.

Manyangadze T, Chimbari MJ, Gebreslasie M, Mukaratirwa S, 2016. Risk factors and micro-geographical heterogeneity of Schistosoma haematobium in Ndumo area, uMkhanyakude district, KwaZulu-Natal, South Africa. Acta Trop 159:176-84.

Olsen A, Kinung'hi S, Magnussen P, 2015. Schistosoma mansoni infection along the coast of Lake Victoria in Mwanza region, Tanzania. Am J Trop Med Hyg 92:1240-4.

Pennance T, Person B, Muhsin MA, Khamis AN, Muhsin J, Khamis IS, Mohammed KA, Kabole F, Rollinson D, Knopp S, 2016. Urogenital schistosomiasis transmission on Unguja Island, Zanzibar; characterisation of persistent hot-spots. Parasit Vectors 9:646.

Savioli L, Dixon H, Kisumku UM, Mott KE, 1989. Control of morbidity due to Schistosoma haematobium on Pemba island; selective population chemotherapy of schoolchildren with haematuria to identify high-risk localities. Trans R Soc Trop Med Hyg 83:805-10.

Savioli L, Mott KE, 1989. Urinary schistosomiasis on Pemba Island: low-cost diagnosis for control in a primary health care setting. Parasitol Today 5:333-7.

Simoonga C, Kazembe LN, Kristensen TK, Olsen A, Appleton CC, Mubita P, Mubila L, 2008. The epidemiology and small-scale spatial heterogeneity of urinary schistosomiasis in Lusaka province, Zambia. Geospat Health 3:57-67.

Simoonga C, Utzinger J, Brooker S, Vounatsou P, Appleton CC, Stensgaard AS, Olsen A, Kristensen TK, 2009. Remote sensing, geographical information system and spatial analysis for schistosomiasis epidemiology and ecology in Africa. Parasitology 136:1683-93.

Simonsen I, Gog JR, Olson D, Viboud C, 2016. Infectious disease surveillance in the big data era: towards faster and locally relevant systems. J Infect Dis 214:S380-5.

Smith CM, Comber SC, Fry H, Bull M, Leach S, Hayward AC, 2015. Spatial methods for infectious disease outbreak investigations: systematic literature review. Euro Surveill 20.

Sun J, Huang H, Xiao GX, Feng GS, Yu SC, Xue YT, Wan X, Yang GH, Sun X, 2015. Spatial distribution of liver cancer incidence 
in Shenqiu County, Henan Province, China: a spatial analysis. Biomed Environ Sci 28:214-8.

Sun LP, Liang YS, Wu HH, Tian ZX, Dai JR, Yang K, Hong QB, Zhou XN, Yang GJ, 2014. A Google Earth-based surveillance system for schistosomiasis japonica implemented in the lower reaches of the Yangtze River, China. Parasit Vectors 223.

Tieu HV, Laeyendecker O, Nandi V, Rose R, Fernandez R, Lynch B, Hoover DR, Frye V, Koblin BA, 2018. Prevalence and mapping of hepatitis $\mathrm{C}$ infections among men who have sex with men in New York City. PLoS One 13:e0200269.

Wang WC, Zhan T, Zhu YF, 2014. A manufacture method of schistosomiasis epidemic maps based on Google Earth. Chin J Schist Cont 26:96-8.

Wang XY, He J, Yang K, Liang S, 2016. Applications of spatial technology in schistosomiasis control programme in the People's Republic of China. Adv Parasitol 92:143-63.

WHO, 2013. Schistosomiasis: progress report 2001-2011, strategic plan 2012-2020. World Health Organization, Geneva,
Switzerland; 22 pp.

WHO, 2018. World Health Organization fact-sheets. Available from: http:/www.who.int/news-room/fact-sheets/detail/schistosomiasis.

Xiao BZ, Meng JX, Wen JY, Dong LG, Xuan Z, Bing L, Xiao JM, 2016a. Establishment of a monitoring database of historical Oncomelania hupensis environments at grass - root level for schistosomiasis prevention based on Google Earth. Chin J Schisto Cont 28:306-9.

Xiao WS, Jian B, Shun XC, Zu WT, Xiao RZ, Yan YC, Bo L, 2016b. Establishment of surveillance and forecast platform of schistosomiasis in key water regions in Hubei Province. Chin J Schist Cont 28:125-7.

Yang K, Sun LP, Huang YX, Yang GJ, Wu F, Hang DR, Li W, Zhang JF, Liang YS, Zhou XN, 2012. A real-time platform for monitoring schistosomiasis transmission supported by Google Earth and a web-based geographical information system. Geospat Health 6:195-203. 